\title{
An Analysis of Fiscal Policy hith Endogenous InVESTMENT-SPECIFIC TeChNOLOGICAL Change
}

\author{
by
}

Gregory W. Huffman

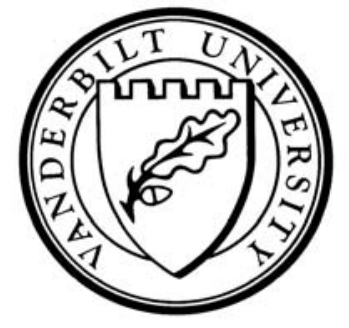

Working Paper No. 08-W01

January 2008

\section{DEPARTMENT OF ECONOMICS \\ VANDERBILT UNIVERSITY \\ NASHVILLE, TN 37235}

www.vanderbilt.edu/econ 


\title{
An Analysis of Fiscal Policy with Endogenous Investment-Specific Technological Change
}

\author{
Gregory W. Huffman*
}

September 3, 2007

\begin{abstract}
The effects of distortional fiscal policies are studied within a model in which there is endogenous investment-specific technological change. Labor is used in the production of output and also for research purposes. Labor or capital taxes then distort the trade-off between developing new technologies, and investing in existing types of capital. It is shown that if there is an externality in the research activity, then it may be socially optimal to impose both a capital tax, and an investment tax credit. The growth rate is shown to be increasing in the rate of capital taxation and decreasing in the rate of labor taxation, although the effect of taxation on the growth rate is modest. This supports the observation that there is relatively little relationship between growth rates of economies, and their rates of taxation.
\end{abstract}

\section{Introduction}

It is common to study the impact of a change in capital or labor taxes by employing a version of the one-sector neoclassical growth model, with neutral technological change. In this a paper an alternative approach is adopted: technological change is investment-specific, and is determined endogenously. Within this model it is shown that the effects of various distortional taxes and subsidies can be quite different than the effects that are normally observed in other more conventional models.

\footnotetext{
*Department of Economics, Vanderbilt University
} 
The model here is a simple version of a neoclassical growth model. However, it also borrows from a related literature. Greenwood Hercowitz and Krusell [4] build on the measurement work of Gordon [2], and show that investment specific technological change is an important ingredient in understanding the source of growth in the US economy. They make the compelling argument that it is falling real prices for new investment goods that accounts for most of the observed growth, with relatively little being left over to be explained by other factors, such as total factor productivity. Greenwood Hercowitz and Krusell [5] then utilize this reasoning to look at certain related business cycle issues. However, in neither of these papers do they explicitly model the mechanism by which the real price of capital falls. Instead, they assume that this is just an exogenous process. In this paper the changing relative price of capital is driven by research activity, which is undertaken by means of labor effort. Increased research spending in one period lowers the cost of producing capital in a subsequent period.

The fact that there are changes in the real price of various capital goods is not news. This has been extensively documented by, among others, Gordon [2] and Jorgenson [10]. The implications that this has for issues such as capital taxation seem unexplored. However, it seems unsatisfactory to take this type of technological change as exogenous. Instead, it is generated by the decisions to engage in a specific amount of research activity, which is presumably an optimallydetermined decision.

It has been shown by others, such as Lucas [13], as well as Stokey and Rebelo [16] that capital taxes on the order of $30 \%$ need not have a substantial impact on the growth rate of an economy. ${ }^{1}$ As Stokey and Rebelo show, there is also empirical support for the notion that the growth rate of actual economies is robust to such a tax change. These models typically rely on the use of human capital to facilitate aggregate balanced growth, and so the tax on physical capital then does not tax human capital. In the model studied here there is no human capital. Nevertheless, it is shown that the impact of a capital tax, such as that of around $30 \%$, will have a negligible impact on the growth rate. In fact, such a tax, though socially welfarereducing, can slightly increase the aggregate growth rate. By contrast a labor tax will reduce the growth rate.

It is commonly thought that there should not be capital taxation in the steadystate, and that such taxation can have serious welfare consequences (e.g. see Chamley [1]) Furthermore, it is generally thought to be unnecessary to have both an investment tax credit and capital taxation simultaneously. Therefore, it is

\footnotetext{
${ }^{1}$ However, the welfare costs of such policies can nevertheless still be substantial.
} 
very puzzling that since WWII, the US government has occasionally both taxed capital, and had an investment tax credit (see Jorgenson and Yun [11]). In this paper it is shown below why the government may wish to impose both of these policies simultaneously in the steady-state. If there is an externality in research, so that each agent's research productivity is positively influenced by that of other agents, then it turns out that a capital tax, together with a judiciously chosen investment tax credit, can attain the socially optimal allocation.

The remainder of this paper is organized as follows. In the next section a growth model is described in which there is also endogenous investment specific technological change. In this model employment in a research sector can lower the subsequent cost of producing new capital. The optimization conditions are studied so as to see how this added feature influences the decisions of agents. Then a version of the model is studied which also has labor and capital taxation. The model is then further modified to incorporate an externality not in the production of output, but in the research effort that produces new vintages of capital. It is shown that to correct this externality, it is possible to attain the optimal allocations through a combination of an investment tax credit, in conjunction with a capital tax. It is then shown that the growth rate is increasing in the capital tax rate, and decreasing in the labor tax rate, though these effects are quite modest. This result is similar to that found by Lucas [13]. Some parametric examples are presented throughout the paper to illustrate the results.

\section{The Model}

In this section we describe a model which with endogenous investment-specific technological change. However, initially it will be useful to describe the basic model without any government taxation. Then distortional taxation will be introduced.

Consider a model populated by identical representative agents with preferences written as follows

$$
\sum_{t=1}^{\infty} \beta^{t}\left[\log \left(c_{t}\right)+\log \left(1-n_{t}\right)\right],
$$

where $c_{t}$ is the level of consumption in period $t$, and $n_{t}$ is the total level of employment. The production technology for the economy is standard, with output $\left(y_{t}\right)$ being produced from capital and labor, and a technology parameter $(A)$. The 
resource constraint for the economy is written as follows:

$$
c_{t}+I_{t}=A k_{t}^{\alpha}\left(n_{1, t}\right)^{1-\alpha} \equiv y_{t} .
$$

Here $k_{t}$ and $I_{t}$ are the capital stock and investment respectively in period $t, \alpha$ is capital's share of aggregate production. Additionally, $I_{t}$ is the amount of investment, measured in units of the consumption good, while $k_{t}$ is measured in units of capital. The variable $n_{1, t}$ represents the amount of employment in producing the consumption good. There are no externalities in production. The production technology is merely the conventional Cobb-Douglas type, and the constant returns to scale feature allows the factors to be paid their marginal products, which then exhausts total output in each period.

The law of motion for the capital stock, which is standard, is written as follows

$$
k_{t+1}=(1-\delta) k_{t}+I_{t} z_{t}
$$

where $\delta$ is the depreciation rate. This equation again illustrates that capital good is not measured in the same units as the consumption good. The variable $z_{t}$ represents a form of investment-specific technological change, as it shows how investment in one period generates capital to be used for subsequent periods. A more efficient or developed technology would have a higher value of $z_{t}$. For future reference it may be useful to denote $z_{t}$ as the level of investment specific technological progress for a firm.

Here we are going to think of the technology parameter $(A)$ as being fixed, but let $z_{t}$ vary, since this is a convenient way to retain some simplicity in the model. ${ }^{2}$

We are going to think of firms as being able to lower the cost of producing capital in the future, by devoting labor effort to research and development, which raises the value of $z_{t}$ in the future. Furthermore, research effort has a prolonged effect over many periods. Let $n_{2, t}$ denote the amount of labor the representative firm devotes to research. Then we will let the relationship between this research

\footnotetext{
${ }^{2}$ This is not to suggest there has been no change in TFP during the post-war period, but there is some evidence that the role of TFP growth in explaining the growth of output may be overstated. Greenwood Hercowitz and Krusell [4] have shown that investment specific tech-

nological change is an important ingredient in understanding the source of growth in the US economy. They show that if one takes into account the falling real prices for new investment goods then this appears to explain most of the observed growth in output, with relatively little residual to be explained by other factors, such as total factor productivity.
} 
effort $\left(n_{2, t}\right)$ and the investment-specific technological change $\left(z_{t}\right)$ be characterized as follows:

$$
z_{t+1}=\Psi\left(z_{t}, n_{2, t}\right) .
$$

We will assume that $\Psi_{1}(\cdot, \cdot)>0, \Psi_{2}(\cdot, \cdot)>0$. The greater is the amount of research activity, the more future capital can be produced from a given amount of investment. An alternative way to say this is that the greater is the amount of research activity, the lower will be the cost of producing new capital in the future. Also, the fact that $\Psi_{1}>0$ reflects the fact that past research has a permanent or long-lasting impact on the future technology. This captures the notion that R\&D discoveries are permanent - they cannot be easily forgotten. It may seem sensible that there should always be some research activity undertaken, and this can be insured if the function has the property that $\frac{\partial \Psi(z, n)}{\partial n} \rightarrow \infty$ as $n \rightarrow 0$. Below we will consider an explicit parameterization for this function.

Another important point to note is that the production technology, given by equation (2.2), also has a companion function, given by equation (2.4) for determining how future capital is produced. That is, these are really "dual technologies." The output from a specific firm has a particular technology for converting its output into capital. In other words, the function given by equation (2.4) is firm-specific, and one firm (or technology) does not benefit from, or utilize the research undertaken by another firm. This assumption prevents the concentration of all research into one firm, and having the externalities utilized by all other firms. However, as is shown in Appendix A, this also means that the optimization problem faced by a firm is now intertemporal or dynamic, rather than a series of static optimization problems.

There is a sense in which the variable " $z$ " then represents the current state of technology, with a higher value for " $z$ " representing a more advanced technology. This framework has the flavor of a quality-ladder type model, but here there are a continuum of steps on the ladder, since rate of technological progress is determined endogenously.

Lastly, the total amount of labor devoted to research and to production must add up to the total amount of work effort:

$$
n_{1, t}+n_{2, t}=n_{t}
$$




\subsection{Optimization Conditions}

The optimization condition with respect to capital accumulation can be written as follows:

$$
\left(\frac{1}{z_{t}}\right)\left(\frac{1}{c_{t}}\right)=\beta\left(\frac{1}{c_{t+1}}\right)\left[A \alpha\left(\frac{n_{1, t+1}}{k_{t+1}}\right)^{1-\alpha}+\left(\frac{1}{z_{t+1}}\right)(1-\delta)\right] .
$$

This is a fairly normal euler equation, adjusted for the fact that the rate at which output is converted into capital $\left(z_{t}\right)$ is potentially changing over time.

The optimization condition with respect to employment is a little more com-

plicated. First we have the usual condition for employment in production $\left(n_{1, t}\right)$, which is written as follows:

$$
\left(\frac{1}{1-n_{t}}\right)=A(1-\alpha)\left(\frac{k_{t}}{n_{1, t}}\right)^{\alpha}\left(\frac{1}{c_{t}}\right) .
$$

Next the condition for employment in research $\left(n_{2, t}\right)$, which is written as follows:

$$
\left(\frac{1}{1-n_{t}}\right)=\sum_{j=1}^{\infty} \beta^{j}\left(\frac{1}{c_{t+j}}\right)\left(\frac{\partial \Psi\left(z_{t}, n_{2, t}\right)}{\partial n_{2, t}}\right)\left(\frac{\partial z_{t+j}}{\partial z_{t+1}}\right)\left(\frac{I_{t+j}}{z_{t+j}}\right) .
$$

The left side of equation (2.8) then is the utility cost of raising $n_{2, t}$, while the right side is the benefit of doing so, and these benefits are all in the future. The return to raising $n_{2, t}$ is the discounted value of the reduction in the real cost of investment in future periods. This extra research employment facilitates an increase in future consumption because the reduced cost of investment engendered by the research. Since the effects of R\&D can be permanent in this framework, increased research activity in one period lowers the cost of producing capital not just in the subsequent period, but in future periods as well.

Another way to write this condition is the following:

$$
\left(\frac{1}{1-n_{t}}\right)=\beta\left(\frac{\partial \Psi\left(z_{t}, n_{2, t}\right)}{\partial n_{2, t}}\right)\left[\left(\frac{1}{c_{t+1}}\right)\left(\frac{I_{t+1}}{z_{t+1}}\right)+\left(\frac{\partial z_{t+2}}{\partial z_{t+1}}\right)\left(\frac{1}{1-n_{t+1}}\right)\right] .
$$

The term on the left side is the marginal utility of leisure, and so in an optimum this should equal the marginal return from engaging in more research, which is given by the right side of this equation. The first term on the right side reflects the fact that research in period $t$ lowers the cost of new capital construction $\left(I_{t+1}\right)$ 
in period $t+1$. The second term reflects the fact that this labor effort is also "labor-saving", and the utility value of this labor is captured in the second term.

Now it is quite conceivable that equation (2.8) might hold with an inequality. That is, one could conceive of a circumstance in which the following equation holds

$$
\left(\frac{1}{1-n_{t}}\right)>\sum_{j=1}^{\infty} \beta^{j}\left(\frac{1}{c_{t+j}}\right)\left(\frac{\partial \Psi\left(z_{t}, n_{2, t}\right)}{\partial n_{2, t}}\right)\left(\frac{\partial z_{t+j}}{\partial z_{t+1}}\right)\left(\frac{I_{t+j}}{z_{t+1}}\right) .
$$

In this instance all employment would be devoted to the production of output, and there would be no research employment because the return to the research activity is too low. If this state of affairs persisted, then there would be no growth, and the economy would eventually converge to some constant level of output. This might occur, depending on the properties of the function $\Psi\left(z_{t}, n_{2, t}\right)$.

\subsection{A Simple Parameterization}

One simple parameterization for the function characterizing the evolution of investment specific technological progress, is the following:

$$
z_{t+1}=\Psi\left(z_{t}, n_{2, t}\right)=B\left(z_{t}^{\gamma}\right)\left(n_{2, t}^{\theta}\right)
$$

where $\gamma \geq 0$, and $\theta \geq 0$. Of course, if $\gamma=1$, then research has a permanent impact on the cost of producing new capital. Not surprisingly, $\gamma=1$ is also the condition necessary for balanced growth (with $\alpha<1$ ). If both $\gamma, \alpha \in(0,1)$, then research employment has a prolonged impact proportional to $\gamma$, but there is only a steady-state without balanced growth. Nevertheless, the costs of labor and capital taxation can then be calculated for such parameterizations. But the effect of taxation on the growth rate, with $\gamma=1$, will be calculated below.

The appeal of this structure and parameterization is that if $\theta=0$, and $B=1$, then this model reverts back to the neoclassical growth model. This will then allow for an easy comparison between these models. Furthermore, if $\alpha=1$, and $\theta=0$ then the model reverts to that of the 'A-K' model.

Another interpretation of this function shown in equation (2.9) is as follows. Suppose there is some stock of discoveries or knowledge, and the size of this at date $t$ is denoted by $z_{t}$. Suppose that the period $t+1$ research knowledge can be augmented by having some labor hired to engage in research. In other words, if $n_{2, t}$ units of labor are employed in research in period $t$, then this results in $(\theta) \ln \left(n_{2, t}\right)$ more units of knowledge in period $t+1$. Let $1-\gamma$ denote the depreciation rate 
of this stock of knowledge, so that knowledge does not last forever. Then the evolution of the stock of knowledge can be written as follows:

$$
\log \left(z_{t+1}\right)=\log (B)+(\gamma) \log \left(z_{t}\right)+(\theta) \log \left(n_{2, t}\right)
$$

\subsection{Another Interpretation}

There is another interpretation of the environment that may be familiar to many. In this environment $q_{t} \equiv\left(1 / z_{t}\right)$ is the cost (or value) of a unit of capital, measured in units of the consumption good. Others have noted the secular fall in this technical rate of substitution (see Gordon [2], Greenwood, Hercowitz, and Krusell [5]). Obviously here the research activity then has a delayed influence on the relative cost of capital.

\section{A Few Special Examples}

There is a special case of the economy described above, which happens to deliver closed-form decision rules. This is the case in which the depreciation rate of capital is $100 \%$ (i.e. $\delta=1$ ).

\subsection{Example \#1}

In this instance the decision rules for this economy are easy to derive, and can be written as follows:

$$
\begin{gathered}
c_{t}=(1-\alpha \beta)\left[A k_{t}^{\alpha}\left(n_{1, t}\right)^{1-\alpha}\right] \\
I_{t}=\alpha \beta\left[A k_{t}^{\alpha}\left(n_{1, t}\right)^{1-\alpha}\right] \\
n_{1, t}=\frac{(1-\gamma \beta)(1-\alpha)}{(1-\gamma \beta)(2-\alpha-\alpha \beta)+\theta \alpha \beta^{2}} \\
n_{2, t}=\frac{\theta \alpha \beta^{2}}{(1-\gamma \beta)(2-\alpha-\alpha \beta)+\theta \alpha \beta^{2}}
\end{gathered}
$$

There is also the special case in which there is balanced growth because $\gamma=1$. In this instance the balanced growth rate of the process for investment specific technological progress is given by the following:

$$
g_{z} \equiv \frac{z_{t+1}}{z_{t}}=B\left(n_{2, t}\right)^{\theta}=B\left[\frac{\theta \alpha \beta^{2}}{(1-\beta)(2-\alpha-\alpha \beta)+\theta \alpha \beta^{2}}\right]^{\theta}
$$


while the growth rate for capital is determined as $g_{k}=\left(g_{z}\right)^{1 /(1-\alpha)}$. It is then easy to see that the growth rate for real output, consumption and investment is given as

$$
g_{y}=\left(g_{k}\right)^{\alpha}=\left(g_{z}\right)^{\alpha /(1-\alpha)} .
$$

Note that the growth rate is not influenced by the parameter $A$. It is prudent to remember that in models of this sort, the growth rate of output is less than the growth rate of capital. This is compatible with balanced growth because capital is measured in different units than output, which is measured in units of the consumption good. Balanced growth is feasible because the real price of capital (measured in units of the consumption good) is falling along a balanced growth path, at the rate of $\frac{z_{t}}{z_{t+1}}=g_{z}^{-1}$.

\subsection{Example \#2}

Suppose again that the depreciation rate of capital is $100 \%$. However, assume that the preferences, instead of being characterized by equation (2.1), are instead written as follows:

$$
\sum_{t=1}^{\infty} \beta^{t}\left[\log \left(c_{t}\right)+\left(T-n_{1, t}-n_{2, t}\right)\right],
$$

where $T$ is the endowment of time. These preferences are linear in labor or leisure, as this characterization was popularized by Hansen [6]. Then the decision rules for consumption are again determined by equations (3.1) and (3.2). However, the decision rules for labor are now written as follows:

$$
\begin{gathered}
n_{1, t}=\frac{(1-\alpha)}{(1-\alpha \beta)} \\
n_{2, t}=\frac{\theta \alpha \beta^{2}}{(1-\gamma \beta)(1-\alpha \beta)}
\end{gathered}
$$

These decision rules for both of these examples would seem to hold even if there were uncertainty or randomness in the parameters $A$ and $B$.

\section{The Model With Taxation}

It is illuminating to study a version of the model which includes both capital and labor taxation. Let $\tau_{k}$ denote the level of capital taxation, and let $\tau_{i}$ be the investment tax credit (or subsidy), while $\tau_{n}$ will be the level of labor taxation. 
We will assume that the government levies taxation on these activities, but then returns the proceeds to agents in the form of a lump-sum transfer.

The optimization conditions associated with optimal employment are written as follows:

$$
\begin{gathered}
A(1-\alpha)\left(1-\tau_{n}\right)\left(\frac{k_{t}}{n_{1, t}}\right)^{\alpha}=\left(\frac{c_{t}}{1-n_{t}}\right) . \\
\frac{\left(1-\tau_{i}\right)}{z_{t}}\left(\frac{1}{c_{t}}\right)=\beta\left(\frac{1}{c_{t+1}}\right)\left[\left(A \alpha\left(\frac{n_{1, t+1}}{k_{t+1}}\right)^{1-\alpha}-\frac{\delta}{z_{t+1}}\right)\left(1-\tau_{k}\right)+\frac{\left(1-\tau_{i}\right)}{z_{t+1}}\right]_{(4.2)} \\
A(1-\alpha)\left(\frac{k_{t}}{n_{1, t}}\right)^{\alpha}\left(1-\tau_{k}\right)=\sum_{j=1}^{\infty} \beta^{j}\left(\frac{c_{t}}{c_{t+j}}\right)\left(\frac{\partial \Psi\left(z_{t}, n_{2, t}\right)}{\partial n_{2, t}}\right)\left(\frac{\partial z_{t+j}}{\partial z_{t+1}}\right) \frac{\left(1-\tau_{i}\right) I_{t+j}}{z_{t+j}}
\end{gathered}
$$

Equations (4.1) and (4.2) are the standard optimality conditions for labor and capital, taking taxes into account. Equation (4.3) is the optimality condition associated with research employment. It says that the value of the employment in producing more output must equal the value of employment devoted to research effort. The $\left(1-\tau_{k}\right)$ term on the left side of this equation reflects the fact that a unit of labor devoted to producing more output produces $A(1-\alpha)\left(\frac{k_{t}}{n_{1, t}}\right)^{\alpha}$ more output. This can then be converted to capital only after paying tax at the rate of $\tau_{k} \cdot{ }^{3}$ On the other hand, if that same unit of labor is devoted to research employment, then this produces $\left(\frac{\partial \Psi\left(z_{t}, n_{2, t}\right)}{\partial n_{2, t}}\right) \frac{I_{t+1}}{z_{t+1}}$ effective units of capital next period, and the discounted value of all future effective units of capital is measured by the right side of equation (4.3). ${ }^{4}$ The right side of equation (4.3) does not have any terms involving $\left(\tau_{k}\right)$ because investment is paid out of retained earnings. The wage tax does not distort this last equation because both types of labor are taxed at the same rate. That is, the wage tax does not distort the decision about how to allocate labor, and only influences the decision of how much (or whether) to work.

\footnotetext{
${ }^{3}$ That is, investment in capital is financed out of retained earnings, and cannot be expensed immediately.

${ }^{4}$ Another interpretation is that the left side is the return from employing labor in existing technologies, while the right side is the return from using labor to develop new technologies.
} 


\section{The Investment Tax Credit}

Periodically, in the post-WWII era, the US economy has had an investment tax credit. Jorgenson and Yun [11] present data showing that the investment tax credit has ranged from zero to $10 \%$ since $1962 .{ }^{5}$ It is usually thought that the presence of an investment tax credit is nothing more than a way to reduce the effective rate of capital taxation. It makes little sense to simultaneously tax and subsidize capital accumulation. ${ }^{6}$ Instead of subsidizing investment, the government could instead just reduce the tax on capital. However, using the model of this paper it is possible to propose another reason for utilizing the simultaneous use of a capital tax, and the investment tax credit.

Researchers are used to considering the effect of externalities in the production of output, whereby individual agents (or firms) would benefit from output generated by others (e.g. Romer [15]). However, in such models capital taxation is especially undesirable. But here we propose an alternative type of externality which can motivate the positive taxation of capital, together with an appropriate investment tax credit. Suppose that instead of having an externality in the production of final output, we consider a research externality so that agents or firms benefit indirectly from the research undertaken by others. It is not difficult to imagine why this might be the case. We certainly witness the agglomeration of researchers, whether they are scientists, engineers, generic academics, into research laboratories or universities. Presumably this is because there are external benefits from this activity. Our purpose here is not to model this agglomeration, but instead to study what the effect might be from this type of externality.

In terms of this model, it makes sense to incorporate this externality by writing the effect of research, instead of through equation (2.9), in the following form

$$
z_{t+1}=\Psi\left(z_{t}, n_{2, t}, N_{2, t}\right)=B\left(z_{t}^{\gamma}\right)\left(n_{2, t}^{\theta}\right)\left(N_{2, t}^{\omega}\right)
$$

Here, $n_{2, t}$ is the quantity of labor effort employed in research by the individual, and

\footnotetext{
${ }^{5}$ This credit has been employed in a rather discriminatory fashion, with some types of investment goods receiving more favorable treatment. Many types of machinery have been eligible for the tax credit, whereas investment in many types of structures has not. More recently, since 1986 the federal government has generally not employed the investment tax credit.

${ }^{6}$ Of course, it is well-known that a capital tax, coupled with a judiciously chosen investment tax credit, amounts to a lump-sum tax on old capital, while leaving new capital untaxed. This would then mean that there is no future distortion to the capital accumulation decision. However, this reasoning would not seem to explain the periodic changes in the rate of capital taxation, and the rate of the investment tax credit.
} 
$N_{2, t}$ is the external effect which represents the average quantity of labor effort in the economy, that is devoted to research effort. Suppose that firms and individuals ignore this external affect on $\left(N_{2, t}\right)$ when they make their employment decisions $\left(n_{2, t}\right)$. Now in the presence of such an externality, the privately optimal allocations will not coincide with the socially optimal allocations. Here the most obvious solution to the problem of the externality is to subsidize the research activity directly. However, it will be shown below that instead of a subsidy for research, the desired allocations could be attained by a combination of an investment tax credit (or subsidy), and a tax on net capital income.

In the absence of any government taxes or subsidies, the individual's optimization condition would be given by equations (2.6), (2.7), and (2.8). However, if there is an externality, as given by equation (5.1), then equation (2.8) will not be the optimization condition that characterizes the social optimum. Instead, the corresponding condition that would hold in the social optimum is the following:

$$
\left(\frac{1}{1-n_{t}}\right)=\sum_{j=1}^{\infty} \beta^{j}\left(\frac{1}{c_{t+j}}\right)\left(\frac{d \Psi\left(z_{t}, N_{2, t}, N_{2, t}\right)}{d N_{2, t}}\right)\left(\frac{\partial z_{t+j}}{\partial z_{t+1}}\right)\left(\frac{I_{t+j}}{z_{t+1}}\right) .
$$

The next issue is to investigate whether it is possible to construct government policies that might support the socially optimal allocations, in the presence of such an externality. One obvious policy would be to have the government institute a subsidy to research, possibly by subsidizing the wages paid to employees working in this sector. However, here we will contemplate an alternative set of policies. Let us consider a government that is imposing a capital tax $\left(\tau_{k}\right)$, and labor tax $\left(\tau_{n}\right)$, and an investment tax credit $\left(\tau_{i}\right)$. In this instance the optimization conditions for capital, labor and research are now written as follows:

$$
\begin{gathered}
A(1-\alpha)\left(1-\tau_{n}\right)\left(\frac{k_{t}}{n_{1, t}}\right)^{\alpha}=\left(\frac{c_{t}}{1-n_{t}}\right) . \\
\frac{1}{z_{t}}\left(1-\tau_{i}\right)\left(\frac{1}{c_{t}}\right)=\beta\left(\frac{1}{c_{t+1}}\right)\left[A \alpha\left(\frac{n_{1, t+1}}{k_{t+1}}\right)^{1-\alpha}\left(1-\tau_{k}\right)+\frac{\delta \tau_{k}}{z_{t+1}}+\frac{\left(1-\tau_{i}\right)(1-\delta)}{z_{t+1}}\right] \\
\left(1-\tau_{k}\right) A(1-\alpha)\left(\frac{k_{t}}{n_{1, t}}\right)^{\alpha}=\sum_{j=1}^{\infty} \beta^{j}\left(\frac{c_{t}}{c_{t+j}}\right)\left(\frac{\partial \Psi\left(z_{t}, n_{2, t}, N_{2, t}\right)}{\partial n_{2, t}}\right)\left(\frac{\partial z_{t+j}}{\partial z_{t+1}}\right)\left(\frac{I_{t+j}}{z_{t+j}}\right)\left(1-\tau_{i}\right)
\end{gathered}
$$

Equations (5.3) and (5.2) are the standard equations for the optimal labor and capital decisions. As can be seen, for a given value of the capital tax $\tau_{k}$, there is 
always a value for the investment tax credit $\tau_{i}$ which will then leave both sides of equation (5.3) at the optimal level (i.e. the capital-labor ratio that would prevail at the social optimum).

Equation (5.4) is then the optimal decision for research. We have also imposed an investment tax credit, and this is denoted by $\tau_{i} \cdot{ }^{7}$

The following Proposition characterizes the set of policies would support the optimal allocations.

Proposition 5.1. In a the steady-state, with the research technology given by equation (5.1), there exists a government policy that delivers the optimal allocations, and this policy has the following characteristics: $0=\tau_{n} \leq \tau_{i} \leq \tau_{k}$, where the inequalities are strict if $\omega>0$.

Proof: See Appendix B.

The proof is by construction. As such, these are unique tax and subsidy rates that support the optimal allocations. That is, given that there are these three policy tools, there are unique values that deliver the optimal allocations. However, there are combinations of other policy tools, that could also accomplish the same goal. These might include research subsidies, or consumption taxes.

The proof above is likely to be much more general that it appears. That is, there seems to be little reliance on the specific production function given by equation (2.2), or the functional for given by equation (2.9). It is easy to show that the result also hold away from the steady-state as well, but he notation is simpler this way.

The externality implies that there is not enough research being undertaken in equilibrium. In other words, the social return on the right side of equation (5.4) is larger than the private return. To get more research, it is beneficial to raise the rate of capital taxation $\left(\tau_{k}\right)$. This raises the cost of using labor in production, and thereby encourages the firm to utilize more labor in research. However, raising the capital taxation rate $\left(\tau_{k}\right)$ now distorts the capital accumulation decision in equation (5.3), and discourages capital accumulation. But this latter distortion can be offset by also employing the investment tax credit. ${ }^{8}$ Hence a simultaneous

\footnotetext{
${ }^{7}$ This should be compared with what you get if you combine equations (2.7) and (2.8).

${ }^{8}$ It is crucial to this argument that the depreciation of capital is tax-deductible, so that the term $\left(\delta \tau_{k} z_{t+1}^{-1}\right)$ is present on the right side of equation (5.3). If this term were absent, then it would be necessary to have $\tau_{i}=\tau_{k}$ in equation (5.3), but the externality in equation (5.4) needs to have $\tau_{i}<\tau_{k}$.
} 
utilization of the investment tax credit and a capital tax can help to offset this research externality.

Another way to think of this result is as follows: A capital tax, accompanied by an appropriate investment tax credit is really equivalent to a subsidy to the research activity. If one does not observe a direct subsidy to an activity, this does not necessarily mean that the subsidy does not exist. Instead, it may merely mean that it is hidden in other taxes or subsidies to related activities.

This is illustrated in Figure 1 where the desired level of the capital tax $\left(\tau_{k}\right)$ and the investment tax credit $\left(\tau_{i}\right)$ as a function of the size of the externality. ${ }^{9}$ Here we are measuring the size of the external effect by ratio of the parameters $(\omega / \theta)$. It turns out that in this example that the optimal level of labor taxation is zero. For a moderate size of the externality $(\omega / \theta \approx .25)$, the capital tax rate is close to $30 \%$, while it is then optimal to have an investment tax credit of around $10 \%$.

Jorgenson and Yun [11] describe the levels of capital taxation and the investment tax credits for the US economy from 1946 until 1986. Their average corporate tax rates are close to $50 \%$ fluctuate very little. Their data for the investment tax credit fluctuate substantially between zero and $10 \%$, but seem to average close to $7 \%$.

House and Shapiro [7] have also updated the work done by Jorgenson and Yun, and compiled a data set for the investment tax credits from 1948 until 2002, for a wide variety of investment goods. While this credit was as high as $10 \%$ in 1985 , it has most recently been zero. ${ }^{10}$ However, many states have investment tax credits, and in many instances these credits are targeted to particular types of investment goods.

From a normative point of view, one might also wish to understand why the investment tax credit, and the capital tax rate should have changed so much over post WWII era. The model suggests that if the size of this research externality should have changed then it would have been appropriate to change these tax parameters. In particular if the size of the externality $(\omega / \theta)$ were to rise (fall), then it would be fitting to raise (lower) the capital tax rate and the investment

\footnotetext{
${ }^{9}$ The parameter values chosen for this example are the following: $\beta=.95, \alpha=.35, A=B=$ $1, \delta=.08, \theta=.20$, and $\gamma=.50$.

${ }^{10} \mathrm{I}$ am grateful to Christopher House for sending me his data set. It should also be noted that accelerated depreciation allowances, which are not included in the model, have essentially the same impact as investment tax credit. Hence, even if the credit is not explicitly in the tax code, the same impact can be generated through this other means.
} 
tax credit. But it is again important to remember that these dual policies are really a roundabout way to encourage research in this environment. This same goal can be achieved in more than one manner.

\subsection{Another Extension}

At this point there is a natural question that arises: How special or important is the assumption that labor is the key input into the development of new types of capital? That is, would the results change materially if capital were an input into equation (5.1)? To be more precise, suppose that the firm's optimization problem, given in Appendix A, is similar. That is, suppose that the firm produces capital $\left(k_{1, t}\right)$ that is used in producing output, and also produced identical capital $\left(k_{2, t}\right)$ that is used for research purposes. Assume that this technology is then written as follows:

$$
z_{t+1}=\Psi\left(z_{t}, n_{2, t}, N_{2, t}, k_{2, t}\right)=B\left(z_{t}^{\gamma}\right)\left(n_{2, t}^{\theta}\right)\left(N_{2, t}^{\omega}\right)\left(k_{2, t}^{\varepsilon}\right)
$$

Then it is possible to show that if investment is again financed out of retained earnings, then the result of the proposition still holds. The reason is that in this case the distortions that are faced by the firm, through either the capital tax or the investment tax credit, do not affect the optimization decision faced by the firm for $\left(k_{2, t}\right)$. The investment tax credit, for example, reduces the cost of producing $\left(k_{2, t}\right)$, but it also reduces the benefit of raising $\left(k_{2, t}\right)$ by the same proportion. This is because the benefit is that the reduced cost of future investment is also offset by the investment tax credit. Hence, it would appear that the result from the proposition is more general than it might first appear.

\section{The Impact of Taxation on Growth}

It is now of interest to investigate how the growth rate of this economy is influenced by these tax rates. To facilitate such a study it is important to have some benchmark against which such a comparison can be made. Figure 2 shows the growth rate of an economy would be influenced by various tax rates, in the case of a Romer-style economy with an externality and with logarithmic preferences, but with the parameters otherwise chosen to be the same as those of our benchmark 
model (i.e. $\beta=.95, \alpha=.35, \delta=.08) .{ }^{11}$ The model is parameterized so that it has a growth rate of $3 \%$ when the tax rates are all zero. The effect that capital taxation can have on the growth rate is clearly seen. Obviously a $30 \%$ tax rate can have a considerable influence on the growth rate of such an economy.

Also shown in Figure 2 is the effect of taxation on the 'A-K' version of the model. This is the case where $\alpha=1$, and where the parameter $A$ is chosen so that it has a growth rate of $3 \%$ when the tax rates are all zero. In this case, the capital tax has an even larger influence on the growth rate. ${ }^{12}$

By comparison, Figure 3 shows how varying these tax rates can have an influence on our benchmark model with investment-specific technological change. The parameter values chosen for this example are the following: $\beta=.95, \alpha=$ $.35, A=1, B=1.49, \delta=.08, \theta=.20$,and $\gamma=.50$. First, it is important to note the dramatically smaller nature of the scale on the vertical axis of this diagram, in contrast with Figure 2. This shows that in this model the growth rate is barely influence by these tax rates at all: an increase in the either of labor or capital tax rate barely changes the growth rate. Furthermore, the labor tax rate has a negative influence on the growth rate, but the capital tax has a small positive influence on the growth rate. The reason for this result is that an increase in the capital tax rate deters capital accumulation, which ordinarily retards growth. But this also encourages more research activity, which can offset this first effect. The labor tax discourages work in producing goods $\left(n_{1}\right)$, which in turn lowers the return to capital accumulation and retards growth. But in this model the labor tax also lowers the return to working in research $\left(n_{2}\right)$ as well, which also helps to lower the growth rate.

That the effects illustrated in Figures 2 and 3 are so different may not be so surprising when one considers the differences in the technology of the two economies. In the A-K model, there is only one technology or sector, which produces output and is the sole "engine of growth." By contrast in the present model, a tax may cause substitution of labor from the sector producing output to the research sector. Such avenues of substitution must inevitably change the quantitative results.

Nevertheless, it should also be noted that neither of these taxes are optimal, since they both create distortions and lower welfare through lower consumption.

\footnotetext{
${ }^{11}$ In other words, the preferences are given by equation (2.1), $z=1$ in each period, but the technology is written as $A_{t} k_{t}^{\alpha}$, but there is an externality such that $A_{t}=K_{t}^{1-\alpha}$, where $K_{t}$ is the average capital stock in the economy, which assumed to be exogenous by each (identical) agent.

${ }^{12}$ But obviously the labor tax has no influence, since labor is not a factor of production.
} 
It is just that the distortional impact on the growth rate does not appear to be too pronounced in this case.

\subsection{Example \#3}

For the economy described above in Example \#1, if there is a capital tax $\left(\tau_{k}\right)$ then the decision rules for this economy can be written as follows:

$$
\begin{gathered}
c_{t}=\left(1-\alpha \beta\left(1-\tau_{k}\right)\right)\left[A k_{t}^{\alpha}\left(n_{1, t}\right)^{1-\alpha}\right] \\
I_{t}=\alpha \beta\left(1-\tau_{k}\right)\left[A k_{t}^{\alpha}\left(n_{1, t}\right)^{1-\alpha}\right] \\
n_{1, t}=\left[\frac{(1-\alpha)}{\left[1-(\beta \alpha)\left(1-\tau_{k}\right)\right]}+\left(\frac{\alpha \theta \beta^{2}}{(1-\gamma \beta)(1-\beta \alpha)}\right)+1\right]^{-1}\left[\frac{(1-\alpha)}{1-(\beta \alpha)\left(1-\tau_{k}\right)}\right] \\
n_{2, t}=\left[\frac{(1-\alpha)}{\left[1-(\beta \alpha)\left(1-\tau_{k}\right)\right]}+\left(\frac{\alpha \theta \beta^{2}}{(1-\gamma \beta)(1-\beta \alpha)}\right)+1\right]^{-1}\left[\frac{\alpha \theta \beta^{2}}{(1-\gamma \beta)(1-\beta \alpha)}\right]
\end{gathered}
$$

It is straightforward to show that the capital tax results in a growth rate for $z_{t}$ of

$g_{z}=B\left[\left[\frac{(1-\alpha)}{\left[1-(\beta \alpha)\left(1-\tau_{k}\right)\right]}+\left(\frac{\alpha \theta \beta^{2}}{(1-\gamma \beta)(1-\beta \alpha)}\right)+1\right]^{-1}\left[\frac{\alpha \theta \beta^{2}}{(1-\gamma \beta)(1-\beta \alpha)}\right]\right]^{\theta}$,

which, of course, is increasing in the capital tax rate $\left(\tau_{k}\right)$.

Now consider the same economy in which there is a labor tax, and the capital tax and investment tax credit are both zero. It is possible to show that the investment and consumption decision rules are unaffected by this. However, the employment decision rules are then as follows:

$$
\begin{gathered}
n_{2}=\left[(1-\alpha)\left(1-\tau_{n}\right)+\left(\frac{\alpha \theta \beta^{2}}{1-\gamma \beta}\right)+(1-\beta \alpha)\right]^{-1}\left[\frac{\alpha \theta \beta^{2}}{1-\gamma \beta}\right] \\
n_{1}=\left[(1-\alpha)\left(1-\tau_{n}\right)+\left(\frac{\alpha \theta \beta^{2}}{1-\gamma \beta}\right)+(1-\beta \alpha)\right]^{-1}\left[(1-\alpha)\left(1-\tau_{n}\right)\right] .
\end{gathered}
$$

In this case employment in production $\left(n_{1}\right)$ is decreasing in the tax rate, while employment in research $\left(n_{2}\right)$ is increasing in the labor tax rate $\left(\tau_{n}\right)$. Of course, this latter result then implies that when $\gamma=1$, when there is growth, the growth rate is a strictly increasing function of the labor tax rate. 


\section{Final Remarks}

The role of endogenous research spending in traditional growth models is a relatively unexplored topic. This is somewhat surprising since it seems undeniable that research into new types of technologies seems manifest in consumer and investment goods all around us. New technologies do not just appear like manna, but instead are the outcome of deliberate decisions. In the model presented here, research effort is measured solely in units of employment devoted to this activity, but it is also shown else where (see Huffman [8]) that interesting effects arise if labor is not a factor, and instead research is measured instead by forgone goods (or capital).

The model studied here suggests that the effects that distortional taxation can have on the growth rate are sensitive to the mechanism by which growth takes place. In this model employment in the research sector essentially generates new types of capital goods, and so the effect of capital or labor taxation can be quite different from what one might normally expect.

It has been a puzzle as to why we witness such persistently high levels of capital taxation when the costs of such a policy appear to be so large. It is also somewhat puzzling that occasionally economies simultaneously tax capital and also subsidize investment through such avenues as an investment tax credit. The model studied here gives a motivation for why such a policy may be quite sensible. Capital taxation may help to offset externalities that result in the under-investment in research. But it also contains another puzzle: If the model's explanation for the use of a capital tax and an investment tax credit are to be taken seriously, then it is a mystery why there would be a tax on labor, since the proposition in the text suggests that this should be set to zero.

\section{References}

[1] Chamley, Christophe, "Optimal Taxation of Capital Income in General Equilibrium with Infinite Lives" Econometrica, (54), (May, 1986), pgs. 607-622.

[2] Gordon, Robert, The Measurement of Durable Goods Prices, Chicago: University of Chicago Press, (1990).

[3] Gort, Michael, Jeremy Greenwood, Peter Rupert, "Measuring the Rate of Technological Progress in Structures" Review of Economic Dynamics, 2(1), (January 1999): pgs. 207-230. 
[4] Greenwood, Jeremy, Zvi Hercowitz, and Per Krusell, "Long-Run Implications of Investment-Specific Technological Change," American Economic Review, 87(3), (June 1997):pgs. 342-362.

[5] Greenwood, Jeremy, Zvi Hercowitz, and Per Krusell, "The Role of Investment-Specific Technological Change in the Business Cycle," European Economic Review, 44(1), (January 2000): pgs. 91-115.

[6] Hansen, Gary, "Indivisible Labor and the Business Cycle" Journal of Monetary Economics, 16, (1985), pgs. 309-327.

[7] House, Christopher L., and Matthew D. Shapiro, "Temporary Investment Tax Incentives: Theory with Evidence from Bonus Depreciation" manuscript, University of Michigan, (September 2004).

[8] Huffman, Gregory W., "Endogenous Growth Through Investment-Specific Technological Change" forthcoming, Review of Economic Dynamics, (2007).

[9] Huffman, Gregory, W., "Propagation Through Endogenous InvestmentSpecific Technological Change" Economic Letters, 84, (2004): pgs. 191-197.

[10] Jorgenson, Dale W., "Information Technology and the U.S. Economy" American Economic Review, 91(1), (March 2001), pgs.1-32.

[11] Jorgenson, Dale W, and Kun-Young Yun, Tax Reform and the Cost of Capital, Oxford University Press, New York, (1991)

[12] Krusell, Per, "Investment-Specific R\&D and the Decline in the Relative price of Capital," Journal of Economic Growth, 3, (June, 1998):pgs. 131-141.

[13] Lucas, Robert E. Jr. "Supply-Side Economics: An Analytical Review" Oxford Economic Papers, 42, (April, 1990), pgs. 293-316.

[14] Parente, Stephen L. and Edward C. Prescott, Barriers to Riches The MIT Press, (2002).

[15] Romer, Paul M., "Increasing Returns and Long Run Growth," Journal of Political Economy, 94(5) (October 1986): pgs. 1002-1037.

[16] Stokey, Nancy L., Sergio Rebelo, "Growth Effects of Flat Taxes", Journal of Political Economy, 103(3), (June 1995): pgs. 519-550. 


\section{Appendix A}

\subsection{The Firm's problem With Taxation}

Let the problem of the firm be described as follows. Consider a firm that currently has capital stock $k_{t}$ and a level of investment specific technological change denoted by $z_{t}$. To reduce the burdensome nature of the notation, we will dispense with the investment tax credit, or just set $\tau_{i}=0$. Let $v\left(z_{t}, k_{t}\right)$ denote the value function for the firm. Then this firm's optimization problem is written as follows.

$$
v\left(z_{t}, k_{t}\right)=\max _{k_{t+1}, n_{1, t}, n_{2, t}}\left\{\begin{array}{l}
{\left[A k_{t}^{\alpha}\left(n_{1, t}\right)^{1-\alpha}-w_{t}\left(n_{1, t}+n_{2, t}\right)\left(1-\tau_{n}\right)^{-1}\right]\left[1-\tau_{k}\right]-} \\
\left(\frac{1}{z_{t}}\right)\left[k_{t+1}-(1-\delta) k_{t}\right]+\left(\frac{\delta \tau_{k} k_{t}}{\mathbf{z}_{t}}\right)+\left(\frac{1}{1+r}\right) v\left(z_{t+1}, k_{t+1}\right)
\end{array}\right\} .
$$

subject to the constraint that $z_{t+1}=\Psi\left(z_{t}, n_{2, t}\right)$. Obviously, here $r$ denotes the equilibrium interest rate. Note here that the term $\left(\frac{\delta \tau_{k} k_{t}}{\mathbf{z}_{t}}\right)$ reflects the depreciation allowance given by the government. As such the term $\mathbf{z}_{t}$ should be thought of as being distinct from $z_{t}$, although in equilibrium $\mathbf{z}_{t}=z_{t}$. The latter is the cost of producing capital, and is endogenous to the firm. The former is determined by the government, and is taken as given by the firm. Of course, in equilibrium the two are equivalent.

For convenience it is assumed that the tax on wage income is paid by the firm prior to dispensing the labor income to the worker. Therefore, $w_{t}$ is the after-tax wage paid to labor, and $w_{t}\left(1-\tau_{n}\right)^{-1}$ is the before tax wage, which is paid by the firm.

The optimization conditions are written as follows

$$
\begin{gathered}
A(1-\alpha)\left(\frac{k_{t}}{n_{1, t}}\right)^{\alpha}=w_{t}\left(1-\tau_{n}\right)^{-1} \\
z_{t}^{-1}=\left(\frac{1}{1+r}\right)\left[A \alpha\left(\frac{n_{1, t+1}}{k_{t+1}}\right)^{1-\alpha}\left(1-\tau_{k}\right)+\mathbf{z}_{t+1}^{-1} \delta \tau_{k}+z_{t+1}^{-1}(1-\delta)\right] \\
w_{t}\left(1-\tau_{n}\right)^{-1}\left[1-\tau_{k}\right]=\left(\frac{1}{1+r}\right) v_{1}\left(z_{t+1}\right)\left[\frac{\partial \Psi\left(z_{t}, n_{2, t}\right)}{\partial n_{2, t}}\right] \\
=\left(\frac{1}{1+r}\right)\left[\frac{\partial \Psi\left(z_{t}, n_{2, t}\right)}{\partial n_{2, t}}\right]\left(\frac{I_{t+1}}{z_{t+1}}\right)+
\end{gathered}
$$




$$
\begin{aligned}
& \left(\frac{1}{1+r}\right)^{2} v_{1}\left(z_{t+1}\right)\left[\frac{\partial \Psi\left(z_{t}, n_{2, t}\right)}{\partial n_{2, t}}\right]\left[\frac{\partial \Psi\left(z_{t+1}, n_{2, t+1}\right)}{\partial z_{t+1}}\right] \\
= & \sum_{j=1}^{\infty}\left(\frac{1}{1+r}\right)^{j}\left[\frac{\partial \Psi\left(z_{t}, n_{2, t}\right)}{\partial n_{2, t}}\right]\left[\frac{\partial z_{t+i}}{\partial z_{t+1}}\right]\left(\frac{I_{t+j}}{z_{t+j}}\right)
\end{aligned}
$$

Equation (8.1) says that the marginal product of labor must equal the market wage. Equation (8.2) says that the marginal cost of capital must equal the after-tax market return. Equation (8.3) says that the after-tax cost of labor (or real wage) must be equated to the return from engaging more labor in the research activity. This last part is the discounted value derived from a lower cost of producing new investment goods in the future. It is important to note that the left side of this last equation has the term $\left[1-\tau_{k}\right]$. This is because if the firm hires another unit of labor for research, the cost to the firm's profits of this really $w_{t}\left(1-\tau_{n}\right)^{-1}\left[1-\tau_{k}\right]$, because the firm gets to deduct labor costs before paying its capital taxes.

For the functional form given by equation (2.9), we have $\frac{\partial z_{t+i}}{\partial z_{t}}=\gamma^{i}\left(\frac{z_{t+i}}{z_{t}}\right)$, while, $\frac{\partial \Psi\left(z_{t}, n_{2, t}\right)}{\partial n_{2, t}}=\theta\left(\frac{z_{t+1}}{n_{2, t}}\right)$ and so equation (8.3) then becomes

$$
w_{t}\left(1-\tau_{n}\right)^{-1}\left[1-\tau_{k}\right]=\sum_{j=1}^{\infty}\left(\frac{1}{1+r}\right)^{j}\left(\frac{\theta z_{t+1}}{n_{2, t}}\right)\left(\gamma^{j}\right)\left(\frac{I_{t+j}}{z_{t}}\right)
$$

It is straightforward to verify that with the investment tax credit, equations (8.2) and (8.3) become equations (5.3) and (5.4).

Lastly, the consumer then consumes their labor income, plus the after-tax capital income from that period. Therefore, the period $t$ budget constraint for the individual in this problem is then written as follows:

$$
\begin{aligned}
c_{t}= & {\left[A k_{t}^{\alpha}\left(n_{1, t}\right)^{1-\alpha}-w_{t}\left(n_{1, t}+n_{2, t}\right)\left(1-\tau_{n}\right)^{-1}\right]\left[1-\tau_{k}\right]-z_{t}^{-1}\left[k_{t+1}-(1-\delta) k_{t}\right] } \\
& +\mathbf{z}_{t}^{-1} \delta \tau_{k} k_{t}+w_{t}\left(n_{1, t}+n_{2, t}\right) \\
= & {\left[\alpha A k_{t}^{\alpha}\left(n_{1, t}\right)^{1-\alpha}\right]\left[1-\tau_{k}\right]-q_{t}\left[k_{t+1}-(1-\delta) k_{t}\right]+z_{t}^{-1} \delta \tau_{k} k_{t}+w_{t}\left(n_{1, t}+n_{2, t}\right) }
\end{aligned}
$$

Of course, it is straightforward to show that in an equilibrium in which agents can borrow and lend, the following euler equation must hold

$$
\left(\frac{1}{c_{t}}\right)=\beta\left(\frac{1}{c_{t}}\right)(1+r) \text {. }
$$


Also, the following condition must hold for the optimal labor/leisure decision:

$$
\frac{w_{t}}{c_{t}}=\frac{1}{1-n_{t}} .
$$

Substituting equation (8.1) into equation (8.5) yields equation (4.1). Also, substituting equations (8.2) and (8.3) into (8.4) yields equations (4.2) and (4.3) respectively.

It is straightforward to verify that if there is an investment tax credit that subsidizes the firm's investment, then this alters equations (8.2) and (8.3) so that the investment tax credit appears as in equations (4.2) and (4.3).

\section{Appendix B}

\section{Proof of the Proposition}

After some algebra, it can be shown that the steady-state allocations that are produced by the solving the social planner's problem are the following:

$$
\begin{gathered}
z^{-1}=\beta\left[A \alpha\left(\frac{n_{1}}{k}\right)^{1-\alpha}+z^{-1}(1-\delta)\right] \\
A(1-\alpha)\left(\frac{k}{n_{1}}\right)^{\alpha}=\left(\frac{A k^{\alpha} n_{1}^{1-\alpha}-z^{-1} k \delta}{1-n_{1, t}-n_{2, t}}\right) \\
A(1-\alpha)\left(\frac{k}{n_{1}}\right)^{\alpha}=\frac{\beta(\theta+\omega)}{1-\beta \gamma}\left(\frac{\delta k}{z n_{2}}\right)
\end{gathered}
$$

These equations, together with equation (5.1) constitute 4 equations in 4 unknowns $\left(k, n_{1}, n_{2}, z\right)$. Since the value of $n_{2}$ determines the value of $z$ in the steadystate, we can just consider the latter to be a function of the former. Denote the optimal values of these variables to be $\left(k^{*}, n_{1}^{*}, n_{2}^{*}, z^{*}\right)$. Now consider the optimization conditions that are derived in the presence of government taxation:

$$
\begin{gathered}
z^{-1 *}\left(1-\tau_{i}\right)=\beta\left[A \alpha\left(\frac{n_{1}^{*}}{k^{*}}\right)^{1-\alpha}\left(1-\tau_{k}\right)+\left(z^{-1 *} \delta \tau_{k}\right)+z^{-1 *}\left(1-\tau_{i}\right)(1-\delta)\right] \\
A(1-\alpha)\left(1-\tau_{n}\right)\left(\frac{k^{*}}{n_{1}^{*}}\right)^{\alpha}=\left(\frac{A k^{* \alpha} n_{1}^{* 1-\alpha}-z^{-1 *} k^{*} \delta}{1-n_{1}^{*}-n_{2}^{*}}\right) .
\end{gathered}
$$




$$
A(1-\alpha)\left(1-\tau_{k}\right)\left(\frac{k^{*}}{n_{1}^{*}}\right)^{\alpha}=\frac{\beta \theta}{1-\beta \gamma}\left(\frac{\delta k^{*}}{z^{*} n_{2}^{*}}\right)\left(1-\tau_{i}\right)
$$

Now, the trick is to develop a set of tax policies in order to get equations $(9.4)$ - (9.6) to mimic equations (9.1) - (9.3). Notice that equation (9.6) can mimic equation $(9.3)$ if

$$
\frac{\left(1-\tau_{i}\right)}{\left(1-\tau_{k}\right)}=\frac{\theta+\omega}{\theta} \geq 1
$$

which, of course, implies that $0 \leq \tau_{i} \leq \tau_{k}$ when there is an externality present $(\omega \geq 0)$. Furthermore $\omega>0$ implies that $\tau_{i}<\tau_{k}$. Equation (9.4) can then be re-written as follows:

$$
z^{-1 *}[1-\beta(1-\delta)]\left(1-\tau_{i}\right)=\beta\left[A \alpha\left(\frac{n_{1}^{*}}{k^{*}}\right)^{1-\alpha}\left(1-\tau_{k}\right)+z^{-1 *} \delta \tau_{k}\right]
$$

which, using equation (9.7) can be re-written as follows:

$$
z^{-1 *}[1-\beta(1-\delta)]\left(1-\tau_{k}\right)\left[\frac{\theta+\omega}{\theta}\right]=\beta\left[A \alpha\left(\frac{n_{1}^{*}}{k^{*}}\right)^{1-\alpha}\left(1-\tau_{k}\right)+z^{-1 *} \delta \tau_{k}\right]
$$

Now, this equation is really one linear equation in one unknown: $\tau_{k}$. After solving this equation or $\tau_{k}, \tau_{i}$ can be determined from equation (9.7). With $\tau_{k}$ and $\tau_{i}$ now determined, notice that equation (9.5) and (9.2) are identical iff $\tau_{n}=0$. 
Figure 1

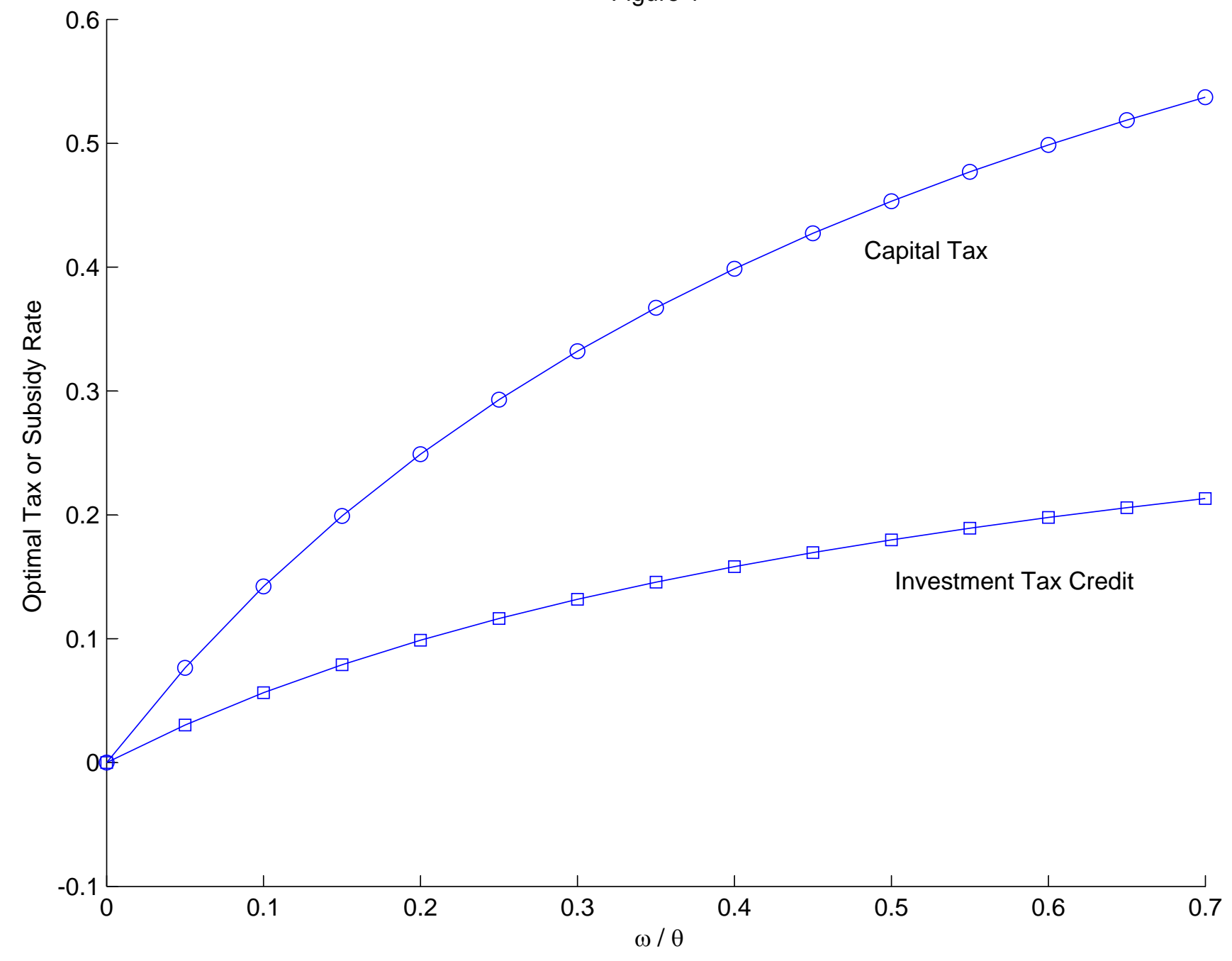


Figure 2

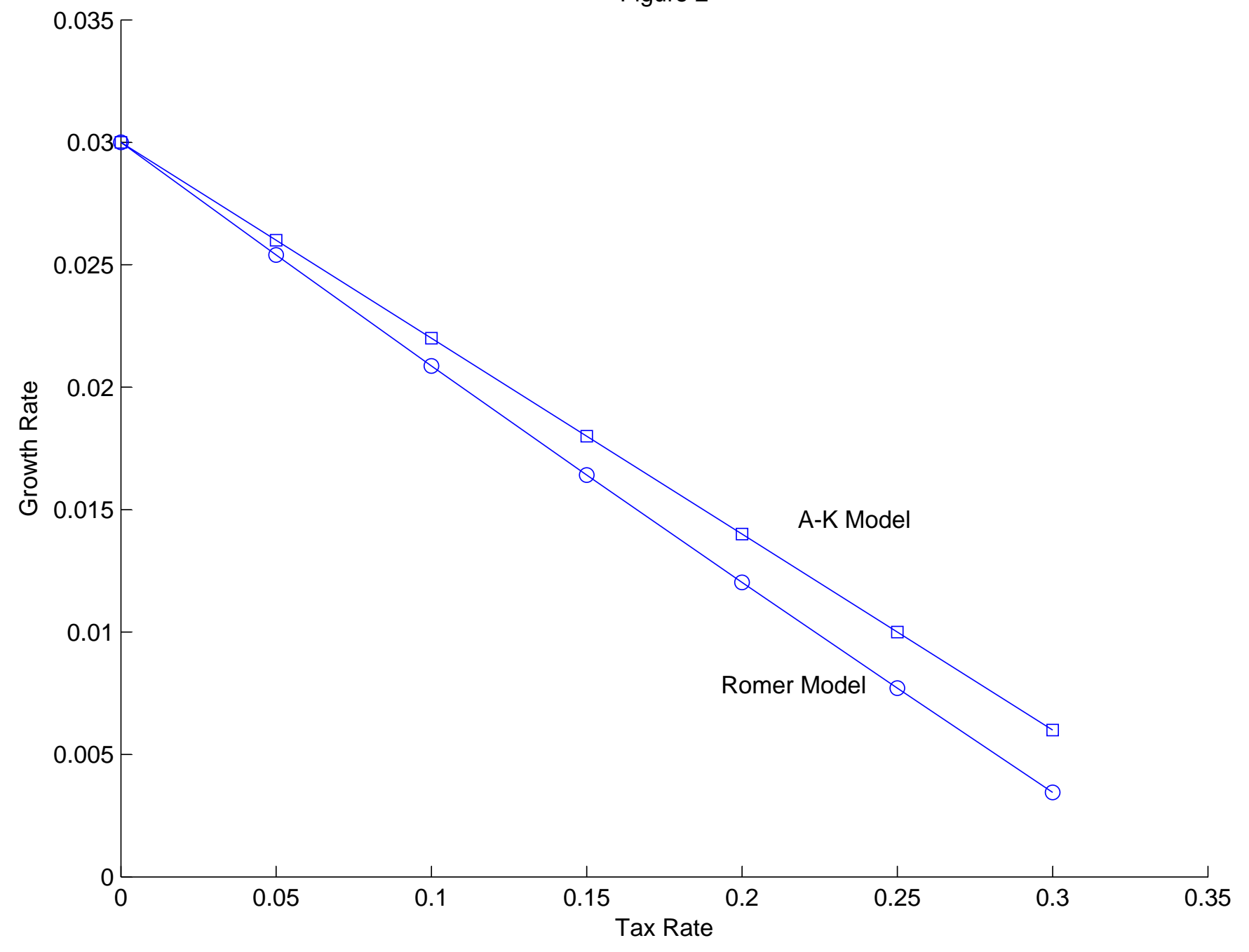


Figure 3

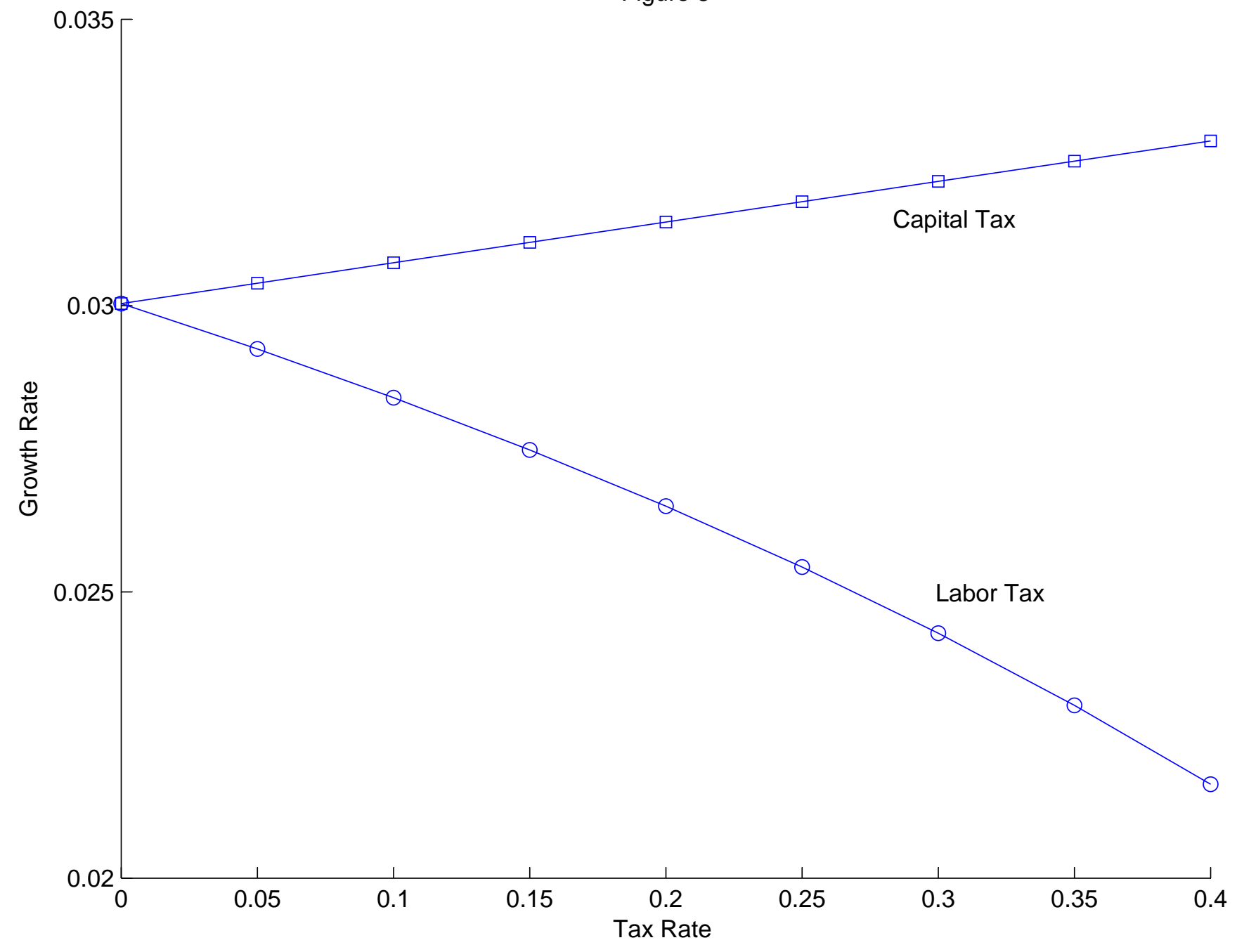

